\title{
DOM QUIXOTE, DORÉ E DALÍ: AS RELAÇÕES ENTRE LITERATURA E PINTURA
}

\author{
Ana Beatriz de Araujo Linardi \\ Doutora em Educação (FE-Unicamp)
}

\begin{abstract}
"Mira, Sancho, por el mismo que denastes juraste te juro - dijo
Don Quijote - que tiene el más corto entendimiento que tiene ni tuvo escudero en el mundo. Que es posible que en cuanto há que andas conmigo no has echado de ver que todas las cosas de los caballeros andantes parecen quimeras, necedades y desatinos, y que son todas hechas al revés? Y no porque sea ello así, sino porque andan entre nosotros siempre una caterva de encantadores que todas nuestras cosas mudan e truecan, $y$ las vuelven según su gusto y según tienen la gana de favorecernos o destruirnos; y, así, eso que a ti te parece bacia de barbero me parece a mi el yelmo de Mambrino y a otro parecerá otra cosa." El ingenioso cavallero Don Quijote de la Mancha, por Miguel de Cervantes Saavedra, 1605.
\end{abstract}

Imagem e palavra: poesia e artes plásticas: quando esses dois sistemas de signos e ou formas expressivas são colocados lado a lado, constatamos que desde o ut pictura poesis de Horacio, que encontrou sua primeira e decisiva mediação no Laocoonte de Lessing, a discussão sempre oscilou, no Ocidente, entre a aproximação e a distância, entre a supremacia de uma ou de outra linguagem. Existe um jogo de atrações que aproximam as duas linguagens e isso deve ter acontecido desde o primeiro signo traçado pelo homem no tronco de uma árvore ou na superfície de alguma obscura caverna.

Dentro do âmbito geral desse debate, não é menos merecedor de interesse, no campo das estéticas comparadas, o caso em que um pintor se volta para "ilustrações" das mais variadas naturezas. A que nos interessa é a de um pintor ilustrando um texto literário, o que resulta no chamado "Livro Ilustrado".

Foram muitos os artistas que se dedicaram, ao longo da história da arte, a realizar esse diálogo com as obras literárias. Botticelli ilustrou a Divina Comédia, Delacroix dedicou seu talento ao Fausto, Paul Klee ilustrou Candide de Voltaire, só para citar alguns exemplos.

Para abordar essa relação, esse estudo estabelece como paradigma uma das obras literárias mais importantes e mais ilustradas da história: o clássico de Cervantes, El ingenioso hidalgo Don Quijote de la Mancha (1605). Os traços precisos traçados por Cervantes induziram inúmeros artistas a 
lançarem-se ao desafio de tornar visíveis seus fascinantes personagens. Destacamos, entre os artistas que voltaram-se para o clássico, Charles Coypel(1694-1752), William Hogarth (1697-1752), Honoré Daumier (18081879), Candido Portinari (1903-1962) e Pablo Picasso (1881-1973).

O escritor Mario Vargas Llosa afirmou que a imortal novela de Cervantes é uma imagem: a de um fidalgo cinqüentenário embutido em uma armadura anacrônica e tão esquelético quanto seu cavalo. Acompanhado por um camponês baixo e gordo, montado em um asno, servindo-lhe de escudeiro, percorrem as paisagens manchegas na busca de aventuras insólitas.

Esse desenho tem sido reproduzido, independente da época ou técnica empregada pelo artista. Seus traços vão contaminando uns aos outros, mantendo viva a imagem do personagem que é um dos mais conhecidos da literatura.

As imagens que retratam os dois personagens não ficaram restritas aos livros. Tapeçarias do século XVII, gravuras, e toda espécie de produção visual retrataram os personagens e os inúmeros episódios cômicos desde a primeira edição da novela. Um dos episódios mais retratados é a famosa passagem do combate contra os moinhos de vento.

Em muitos momentos da obra, Cervantes vale-se de uma "imagem". Valendo-se da relação ut pictura poesis, suas elaboradas descrições e apelos visuais lançaram uma espécie de desafio aos ilustradores para que conferissem visibilidade ao texto.

Graças ao modo como Cervantes caracterizou seus dois personagens, seus traços físicos puderam ser captados com a maior clareza de contornos. Conforme o escritor Jorge Luis Borges, "poderiam perder-se todos os exemplares do Quixote, em castelhano e nas traduções; poderiam perder-se todos, mas a figura de Dom Quixote já é parte da memória da humanidade."

Essa sensação de "realidade" em relação a Dom Quixote e Sancho, aliada a uma grande proliferação de imagens fez com que a novela se tornasse tão conhecida, que muitas pessoas acreditam ter lido o livro em algum momento da vida, no entanto sem tê-lo feito, por saber descrever tão bem as características físicas e "psicológicas" do personagem.

Mas Dom Quixote metamorfoseou-se ao longo dos séculos. Sua imagem acompanhou as transformações do espírito de cada época em que foi ilustrado.

Se as imagens no início queriam ampliar a diversão do texto tornando visíveis os episódios cômicos, o olhar dos artistas foi 
paulatinamente focando-se na dupla de personagens. Os neo-classicistas, ao impregnar as ilustrações com um gestual solene e elementos simbólicos, transformaram Dom Quixote em um cavaleiro libertário. No século XIX e no século XX o fidalgo foi transportado ao mundo do delírio e, finalmente submerso na loucura, um delirante personagem surrealista pelas mãos do pintor Salvador Dalí.

Pontuamos dois momentos da ilustração de Dom Quixote que trazem importantes contribuições para a compreensão dessa interação entre as duas linguagens que se dá no interior do livro.

Num primeiro momento, o século XIX, no período de valorização e difusão das edições ilustradas, o trabalho do artista Gustave Doré (18321883). Em 1863, Doré produziu para o que considerou como síntese da obra, 375 desenhos. Dessa forma o gravurista transpõe, nas categorias de imagens que ele insere no texto, a quase totalidade de informações que a obra literária fornece, com precisão documental. No auge do Realismo, Doré conseguiu atender ao desejo da burguesia que ainda cultuava a estética romântica. Seu desenho preciso, detalhista e sua grande capacidade de manipular texturas e matizes, conseguiu imprimir uma atmosfera quase sobrenatural por meio de jogos fascinantes de luz e de sombra. É importante ressaltar que nenhum outro artista imprimiu sua marca em um personagem literário como Doré ao Dom Quixote. Embora separado por séculos, houve uma junção, no imaginário popular, da figura desenhada no século dezenove com a obra de Cervantes.

A tradição da ilustração considerava que a imagem deveria falar tanto quanto, e junto com o texto. As imagens organizavam-se em seu interior em categorias, com a preocupação de documentar o rosto do herói, os lugares por onde ele transitava. A norma estabelecia um paralelismo semântico e estrutural entre imagem e texto. Em passagens narrativas ou descritivas, a figura surgia habitualmente junto à passagem de referência, de modo a duplicar o que as palavras estavam mostrando. Essa forma de ilustrar permaneceu até a metade do século XIX, quando então a ilustração passou a seguir outros propósitos, como veremos mais adiante.

Como o artista almejava realizar uma síntese da obra em imagens, da maneira como ele a ilustrou podemos fazer uma leitura somente através delas, como se fossem parte de um story-board ${ }^{1}$ que antecipa a filmagem de uma seqüência cinematográfica.

\footnotetext{
${ }^{1}$ Sucessão de desenhos que sintetizam os planos de uma determinada sequência fílmica.
} 


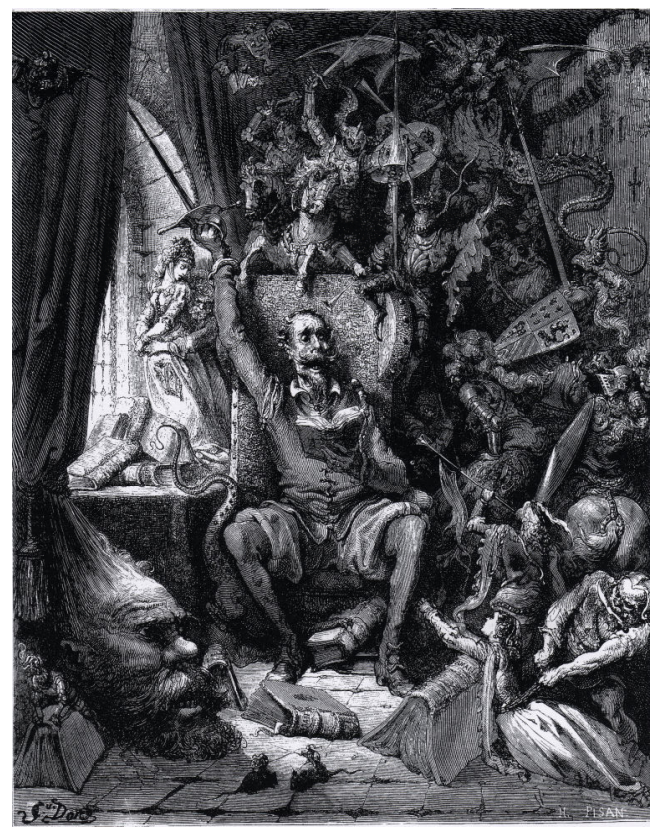

O artista nos apresenta o fidalgo com as marcantes características que Cervantes lhe imprimiu, a silhueta alta e magra, o rosto encovado. Porém por mais decadente que Cervantes pinte o personagem, o desenho de Doré lhe imprimiu uma elegância que parece conduzir a história para o palco de um teatro encenado no interior de um elegante palácio. Apesar da preocupação do artista em adicionar o máximo de elementos presentes no texto, podemos observar que o cômico, o burlesco, foi praticamente suprimido. Doré, como herdeiro dos românticos inscreve-se na linhagem inaugurada por Hugo. O cômico e o burlesco são incorporados à sua estética e, a eles, é atribuída uma certa elegância. No texto de Cervantes, o que é grotesco vem exatamente das situações em que a grandeza e a dignidade são anuladas: o heróico cavaleiro é, na verdade, um pobre desdentado. E é exatamente isso que Doré irá suprimir em relação à figura de Dom Quixote.

Por outro lado, o grotesco, no sentido satírico, aparece ligado a outros personagens, como por exemplo a Sancho. Na primeira aparição de Sancho na obra, há uma flagrante analogia entre o escudeiro e seus familiares, com os animais, associação comum da época às classes sociais mais baixas. Esse contraste visa, no entanto, evidenciar as qualidades 
nobres de Dom Quixote. Doré retrata o personagem trazendo incorporadas as qualidades atribuídas a ele pelo Romantismo: o nobre herói, o idealista.

Doré não nos convida a delirar com Dom Quixote em suas aventuras. Os moinhos de vento não são gigantes nas gravuras, continuam a ser moinhos de vento. Doré se coloca a serviço do texto e, numa relação dialética, o texto é a moldura do desenho, ao mesmo tempo em que o desenho se estabelece como moldura do texto. Doré tratou Dom Quixote como personagem real, nos deu seu retrato e documentou suas aventuras.

Se por um lado, ao tentar encerrar a essência do personagem em seus contornos, congelou uma certa mobilidade que faz com que o personagem se atualize a cada nova leitura, por outro lado, o personagem "flexível como uma letra" continuou sua metamorfose.

Outro momento de nosso estudo foca-se na relação entre pintura e literatura na modernidade. Para isso, o trabalho de Salvador Dalí (19041989) e sua diferenciada aproximação do Quixote, traça um panorama do movimento surrealista.

Atentos a uma nova relação entre texto e imagem, desvinculados dos processos simbólicos tradicionais, os surrealistas buscaram, na criação de seus livros, um jogo ousado de simultaneidades que alterou o estatuto semântico do verbal e do visual. Um exemplo disso são as parcerias que atuaram na produção do livro tipicamente surrealista, como o trabalho de paul Eluard e Man Ray em Facile, onde os poemas eram inseridos nas fotografias, nas quais os contornos de corpos nus ditavam a diagramação. Como a colaboração se dava na gênese do livro ilustrado, com as imagens e o texto nascendo simultaneamente, fica difícil saber se neste caso cabe a utilização do termo "ilustração".

Os artistas do movimento aproveitaram a liberdade a eles concedidas pelo texto e responderam com intensidade às provocações suscitadas por ele. A preocupação dos artistas não era traduzir o texto, mas assegurar a continuidade de seu fantasma, ou a produção de uma espécie de eco distorcido. Apesar da multiplicidade de obras ilustradas produzidas pelos surrealistas, todas elas têm em comum um contexto de metamorfoses e justaposições, não importando a época ou estilo do texto em questão. Essas imagens fazem com que o leitor vivencie essa dissolução dos processos tradicionais e as relações estáveis. Ao invés de considerar o texto como um modelo para o qual têm que providenciar um signo visual equivalente, tratam-no como um estímulo para sua imaginação, colocandoo em contato com suas próprias obscuras e remotas forças inconscientes. 
O livro surrealista tende a negar os traços e a referencialidade do mundo reconhecível e assim o leitor é jogado, de uma cômoda aderência, para um universo marcado pela transformação, numa desconcertante paisagem onde novos elementos emergem. Dessa forma o leitor é forçado a uma série de perturbações que o convidam ao prazer estético de decodificar um artifício oculto.

A relação gráfica de Dalí com Cervantes iniciou-se em 1945, época em que o pintor estava vivendo em Nova Yorque, então o grande centro das vanguardas artísticas. Seu pai lhe enviou uma carta que parece ter sido crucial para iniciar o empenho do artista que, tocado pelas palavras "Es una obra en la que tus facultates podrán sobresalir extraordinariamente", imediatamente iniciou uma série de experimentações que resultou na ilustração da obra.

Tendo em mente que o pintor pertence a um movimento que desconsiderava as relações tradicionais da ilustração e que valorizava a imagem como fundamental para a libertação dos lugares-comuns, já podemos antecipar a entrada na obra literária mediada por uma estética que valorizava os mecanismos dos sonhos, que apresenta todas as surpreendentes justaposições e estranhamentos surrealistas e que também fazem referência à psicanálise freudiana. Porém Dalí ainda vai mais longe. Subvertendo o instituído, no sentido mais amplo possível da relação de ilustrações dentro de um livro, Dalí apresenta um projeto bem ousado.

Não há uma única edição ilustrada pelo pintor espanhol, mas várias. E cada edição é diferente das demais. A novidade começa no fato do pintor ter se proposto a ilustrar a mesma obra em momentos diferentes. A primeira edição ilustrada por Dalí saiu em 1946 e contou com 38 pranchas e cinco desenhos destinados a acompanhar a primeira parte da obra. Em 1955 ele retomou o tema e produziu outras gravuras. Em 1956 ele realizou um portfólio composto por 12 gravuras. E em 1964 produziu uma nova série de pranchas destinadas a acompanhar a segunda parte. Conforme Dalí produzia gravuras em torno do Quixote, as edições as incorporavam. Tanto é que uma edição de 1964 traz todos esses conjuntos de imagens, com um detalhe: Dalí deu liberdade aos editores para que dispusessem as gravuras conforme achassem conveniente. Por isso não existe o tradicional projeto gráfico para uma exata colocação das ilustrações dentro do texto. A importante tarefa do ilustrador de definir pontos estratégicos para as imagens foi entregue ao editor. A mediação deste outro profissional rompe com o privilégio que antes cabia ao ilustrador e o trabalho passa a ter um caráter mais coletivo. Mas o papel principal é, na verdade, do leitor, que pode fazer uma livre associação das imagens com o texto, uma vez que elas 
não remetem a nenhum momento específico, mas a todos os momentos. Dalí afirma, por meio de sua atitude que as duas artes subsistem por conta própria. Não é necessário ler o texto para entender a obra pictórica sobre o Quixote. Da mesma forma, não é preciso ter as imagens para usufruir do texto de Cervantes. Dalí trabalha com a essência de Dom Quixote. E é nesse encontro de duas artes independentes que dá-se um processo de iluminações mútuas.

O procedimento de Dalí deixa de ser, dessa forma, uma ilustração no sentido convencional, porque por mais que evoquemos a liberdade do ilustrador, ainda hesitamos em enfrentar a imagem em si, cercada de múltiplos sentidos possíveis. Talvez por isso os editores insistam em ancorar as imagens no texto "escolhendo" suas localizações de acordo com critérios pessoais.

Dalí possivelmente concebeu a leitura ideal de seu Quixote: o leitor leria a obra de Cervantes em uma sala em que estivessem dispostas todas as imagens, criando assim um duplo envolvimento. Arriscamos ainda que uma edição ideal do Quixote de Dalí seria uma edição em dois volumes: uma para o texto, outra para as imagens. O leitor poderia acessar as imagens em paralelo e com independência, mas sem perder a relação entre as duas. Essa relação será estabelecida na leitura individualizada, e cada leitor terá sua própria experiência. O leitor poderia fazer a junção onde e como quiser, multiplicando as possibilidades de leitura. Um Quixote a cavalo não se prende a um determinado momento, mas a todas as situações em que o texto se refere ao Quixote a cavalo. As próprias ilustrações vão assumindo significações diferentes ao longo da leitura e nas diferentes edições. Podemos então resumir a proposta de Dalí como a apresentação de um mesmo universo olhado por duas artes diferentes. $\mathrm{O}$ artista nos apresenta um manifesto em prol das potencialidades das imagens, numa mobilidade que nos remete poeticamente ao cinema, permitindo ao leitor que monte o seu próprio filme.

Dalí trabalha com diversas técnicas artísticas, num processo de experimentações que vão gerando não um único Quixote que percorre o livro, mas vários. Seja em manchas de aquarelas que transfiguram-se diante do leitor, seja numa figura em vertiginosa espiral, desantropormofizado ou um ser descarnando, vários Quixotes trazem para o leitor as mais diversas associações, referências, citações e diálogos.

Lembremos que a própria obra gerou vários desdobramentos. Foi inicialmente, recebida como uma sátira aos livros de cavalaria bastante difundidos na Europa. Posteriormente, os iluministas a leram como uma 
sátira contra a imaginação e fantasia para exaltar a razão. Já os românticos transformaram-na numa apologia da imaginação livre, contra a razão prosaica. Uma vertente existencialista vê na obra, no século XX, uma manifestação da solidão do homem, do caos da realidade e da desilusão que nutre o pensamento e a arte. Dalí evoca todas essas possibilidades de leitura: há elementos grotescos e cômicos, há cavaleiros libertários, há seres despedaçados, enfim, toda uma bagagem que foi incorporada à obra de Cervantes ao longo de sua existência, nas milhares de vezes em que foi comentada e analisada, nas interpretações e apropriações divergentes ao longo do tempo. Dessa forma, Dalí oferece ao leitor uma possibilidade de interferência, no confronto das imagens que dão a ele a chance de contemplar e refletir sobre essa bagagem histórica e significativa incorporada à obra. Por isso não é possível que o personagem seja retratado da mesma forma do começo ao fim. Essa multiplicidade de perspectivas adequa-se à multiplicidade de facetas do personagem. Ora um herói, um tolo, um sábio, um louco ou santo, nenhuma das facetas dá conta de sua personalidade.

Em todo o texto tanto os personagens quanto os objetos ou animais, apresentam a característica de multiplicar suas aparências. O Bacharel Sansón Carrasco torna-se o Cavaleiro dos Espelhos e depois o Cavaleiro de la Blanca Luna. A camponesa Aldonza torna-se Dulcinea del Toboso. Moinhos tornam-se gigantes, assim como rebanhos de carneiros tornam-se exércitos. O próprio Dom Quixote, que antes era Don Alonso, torna-se o Cavaleiro da Triste Figura. Dalí trará ao leitor o contágio da loucura de Dom Quixote, fazendo com ele compartilhe com os delírios do personagem através dessa mobilidade que marcam suas imagens. As visões e os delírios são compartilhados e por vezes é o próprio leitor que "alucina", como é o caso das ilustrações em que se contempla o personagem, que por sua vez contempla uma paisagem surrealista que se move à sua frente, com um particular: o próprio Dom Quixote é o produto alucinado da mente do artista. Como que contaminado pelo processo de magia, o leitor adentra esse universo alucinatório. Ao contrário de Doré, para Dalí os moinhos são gigantes, e assim é que são retratados.

A relatividade da fronteira entre o real e o fictício, a junção de fatos com visões, o "real" transformado em "coisa", são comuns tanto na obra de Cervantes quanto nas postulações do movimento surrealista. O personagem sabe que traz na cabeça uma bacia de barbeiro, mas quer vê-la como um objeto mágico, o elmo de Mambrino. Não é a toa que em muitas das imagens de Dalí há analogias do personagem com o artista, mais 
especificamente o pintor. Há uma ilustração em especial, em que, o personagem de perfil, segurando uma lança e seu escudo nos provoca, num movimento de duplicação da imagem que Dalí praticava como princípio, a figura de um pintor que carrega suas armas: o pincel e a paleta. Há talvez uma alusão, nesse momento, mesmo que inconsciente por parte do artista, de que os encantadores de Dom Quixote que providenciam as transformações no tecido da realidade possam ser comparados aos artistas, "cuja função é a de garantir a coexistência e a compatibilidade de diversos universos de significados" 2 . Afinal, os artistas podem fazer uma bacia de barbeiro tornar-se o elmo de Mambrino.

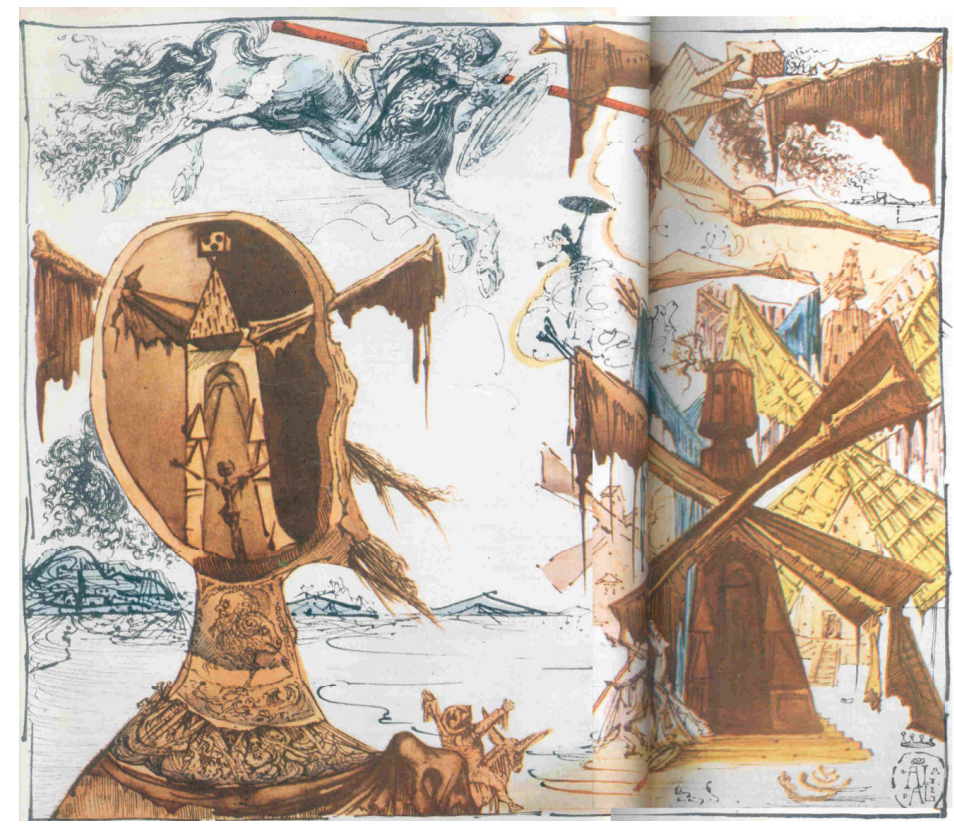

Dessa forma, o estatuto do semântico do visual e do verbal foi transformado. Os limites entre a semelhança e a diferença se tocam e se transformam em algo indefinível, espécie de repouso de uma essência do poético.

\footnotetext{
${ }^{2}$ Bernardi, Gustavo. Verdades Quixotescas. São Paulo: Annablume, 2006.
} 
Lembremos que Dalí realizou esse trabalho num momento em que as artes passaram a funcionar juntas. As experiências artísticas do século $\mathrm{XX}$ levaram as artes ao encontro de suas especificidades, de suas identidades próprias.

$\mathrm{O}$ artista, ao proceder com sua arte, pode valer-se dos recursos que anteriormente pertenciam ao reduto da arte vizinha. Então é natural que a poesia e a pintura se relacionam de uma maneira diferente. Não é necessário que a ilustração esteja apenas pontuando o texto, mas que estabeleça com ele uma relação nova. Isso porque a leitura do homem do século XXI já está treinada o suficiente para perceber e compreender essas novas relações. Dalí apontou outros caminhos além da proposta tradicional de aproximação de um texto literário com uma proposta que não exclui a antiga, mas que acrescenta a ela uma nova possibilidade.

Dalí apontou outros caminhos de aproximação de um texto literário. A questão não é simplesmente visualizar o Dom Quixote, mas recriá-lo poeticamente na intersecção entre texto e imagem. É um ir além da pura e simples representação.

Não importa se é palavra ou imagem, mas a poética no sentido mais amplo do termo.

\section{Bibliografia}

BERNARDO, Gustavo.Verdades Quixotescas. São Paulo: Annablume, 2006.

CERVANTES, Miguel de. Dom Quixote de la Mancha (tradução de Miguel Serras Pereira, ilustrações de Salvador Dalî). Lisboa: Edições Dom Quixote, 2005.

Belo Horizonte: Itatiaia, 1997. O engenhoso fidalgo Dom Quixote de la Mancha (ilustrações de Gustave Doré). . Don Chisciotte della Mancha, Illustrata da Salvador Dali. Milano: Aldo Pallazzi, 1964

Don Quijote de la Mancha. Edición del IV Centenario. España: Real Academia Española/Asociación de Academias de la lengua española, 2005.

GONÇALVES, Aguinaldo José. Laokoon Revisitado. São Paulo, Edusp, 1994.

HUBERT, Renée Riese. Surrealism and the book. USA: California University Press, 1988.

MORAES, Eliane R. O corpo impossivel. São Paulo: Iluminuras, 2002.

NADEAU, Maurice. Histoire du surréalisme. Paris: Editions du Seuil, 1964.

VIEIRA, Maria Augusta da Costa. O dito pelo não-dito, paradoxos de Dom Quixote. São Paulo, Edusp, 1998. 